Abstract THU0761-HPR - Table 1

\begin{tabular}{|c|c|c|c|c|c|c|c|c|c|}
\hline Indication & Time (months) & $\mathrm{ABA}$ & $\mathrm{ADA}$ & CERTO & ETN & GOLI & IFX & RTX & TCZ \\
\hline \multirow[t]{5}{*}{$\mathrm{RA}$} & $\bar{x}$ & 29,7 & 58,6 & 28,8 & 57,4 & 24,6 & 27,3 & 60,5 & 35,7 \\
\hline & ED & 22 & 42,5 & 17,7 & 39,7 & 20,4 & 25 & 32,8 & 27,1 \\
\hline & 1 -year (\%) & 98 & 93 & 89,6 & 98,5 & 77,8 & 94,4 & 97,8 & 88,4 \\
\hline & 1-year Cl95\% & $0,942-1$ & $0,881-0,981$ & $0,805-0,998$ & $0,968-1$ & $0,6076-0,996$ & $0,844-1$ & $0,937-1$ & $0,812-0,963$ \\
\hline & p-value & $<0,001^{*}$ & $0,011^{\star}$ & $<0,001^{*}$ & & $<0,001^{*}$ & 0,115 & $0,005^{\star}$ & $<0,001^{\star}$ \\
\hline \multirow[t]{5}{*}{ PA } & $\bar{x}$ & & 43,4 & & 59,6 & 37,3 & 51,8 & & \\
\hline & ED & & 33,7 & & 46,6 & 19,1 & 27,5 & & \\
\hline & 1-year (\%) & & 87,8 & & 99 & 91,7 & 100 & & \\
\hline & 1-yaer Cl95\% & & $0,802-0,961$ & & $0,971-1$ & $0,831-1$ & & & \\
\hline & $p$-value & & $0,025^{*}$ & & 0,894 & $0,007^{\star}$ & & & \\
\hline \multirow[t]{5}{*}{ EA } & $\bar{x}$ & & 43,1 & & 54,2 & 33,7 & 51,4 & & \\
\hline & ED & & 32,2 & & 37,1 & 16,7 & 47,6 & & \\
\hline & 1-year (\%) & & 95,6 & & 95,8 & 100 & 93,5 & & \\
\hline & 1-year Cl95 & & $0,921-0,991$ & & $0,923-0,995$ & & $0,853-1$ & & \\
\hline & $\mathrm{p}$-value & & $0,04^{*}$ & & $0,008^{\star}$ & & 0,06 & & \\
\hline
\end{tabular}

Disclosure of Interest: None declared

DOI: 10.1136/annrheumdis-2017-eular.5810

\section{THU0762-HPR ONLINE CONSULTATION FOR CHINESE PATIENTS WITH RHEUMATIC DISEASES BASED ON SMART SYSTEM OF DISEASE MANAGEMENT (SSDM) MOBILE TOOLS: A STUDY OF MEDICAL ECONOMICS}

F. Xiao ${ }^{1}$, Z. Guo ${ }^{2}$, Z. Zhang ${ }^{3}$, W. Min ${ }^{4}$, Y. Tang ${ }^{5}$, X. Duan ${ }^{6}$, L. Mo $^{7}$, H. Wu ${ }^{8}$, X. Xu ${ }^{9}$, Y. Zhao ${ }^{10}$, F. Jiang ${ }^{11}$, H. Xiao ${ }^{1}$, Y. Zhao ${ }^{1}$, Y. Jia ${ }^{1}$, F. Zhang ${ }^{12} .{ }^{1}$ Medical Department, Shanghai Gothic Internet Technology Co., Ltd., Shanghai;

${ }^{2}$ Department of Rheumatology, The First People's Hospital of Huainan City, Huaian; ${ }^{3}$ Department of Rheumatology and Immunology, Linyi people's Hospital, Linyi; ${ }^{4}$ Department of Rheumatology and Immunology, Heze Municiple Hospital, Heze; ${ }^{5}$ Department of Rheumatology and Immunology, Yantai YuHuangDing Hospital, Yantai; ${ }^{6}$ Department of Rheumatology and Immunology, The Second Affiliated Hospital of Nanchang University, Nanchang; ${ }^{7}$ Department of Rheumatology, The First Affiliated Hospital of Xi'an Jiao Tong University, Xi'an; ${ }^{8}$ Department of Rheumatology and Immunology, Dongguan People's Hospital, Dongguan; ${ }^{9}$ Department of Rheumatology and Immunology, Changhai Hospital, Shanghai; ${ }^{10}$ Department of Rheumatology and Immunology, First Affiliated Hospital of Harbin Medical University, Harbin; ${ }^{11}$ Department of Rheumatology and Immunology, Huzhou Third People's Hospital, Huzhou; ${ }^{12}$ Department of Rheumatology and Immunology, Peking Union Medical College Hospital, Beijing, China

Background: China doesn't have efficient primary medical care and referral system. Patients can choose any hospitals or any doctors they like to seek medical care. As a result, most patients with rheumatic diseases rushed to a few large cities. Survey shows that more than $40 \%$ of the rheumatic disease patients are unnecessary to go to hospital and they only need advices from specialist. Smart System of Disease Management (SSDM) is a series of applications for chronic diseases management, which develop the interaction between doctors and patients. Our previous study showed that rheumatoid arthritis (RA) patients can master the SSDM and perform self-management after training, including disease activity score with 28 joints (DAS28) and health assessment questionnaire (HAQ) evaluations, as well as medication and lab test data entries.

Objectives: To evaluate the feasibility and benefit of the medical economics of online consultation based on SSDM by rheumatologist.

Methods: The rheumatologists implemented the education and training programs on patients in using SSDM and assist the patients in downloading SSDM mobile application. The SSDM includes doctors' and patients' applications. After data entry, patients can synchronize data to their authorized doctor. On the basis of these data, the rheumatologists can accept the request from their follow-up patients through SSDM and practice consultation in the form of text or telephone call.

Results: From February 2015 to January 2017, 333 rheumatologists supplied 3,119 patients (RA $46 \%$, systemic lupus erythematosus $22 \%$, ankylosing spondylitis $12 \%$, Gout $11 \%$, osteoarthritis $4 \%$, other rheumatic diseases $5 \%$ ) with 136 times free and 3,556 paid consultations. Paid consulting included 3,537 times text Q\&A and 19 telephone consultations. The consulting fee ranged from RMB 10 to 500 yuan (EUR: $R M B=1: 7.33$ ) each in average of $121.3 \pm 55.19$ yuan, which rate match the registration fee in hospital. The total collection of fee for consultations was 399,320 yuan RMB. $35.9 \%$ patients receiving online consultation lived in different city with the rheumatologists. If patients seek medical in hospital, in addition to the registration fees and medical expenses, the mean cost of transportation, accommodation, meals and lost wages was $552.68 \pm 477.51(200-2,800)$ yuan. The total of cost for all patients would have been 2, 509,920 yuan RMB, which is 6.29 times compare with the cost of online. Through the SSDM system for online consultations, patients can save $84.09 \%$ of the cost. Survey shows all patients were satisfied and $60.28 \%$ of them were "very satisfied" with the consultations. Conclusions: Using SSDM system to obtain online consultation, Chinese patients with rheumatic disease can enjoy reduced cost with high satisfaction. In the era lack of primary care system in China, SSDM may serve a complimentary platform to control medical care cost, as well as relieve the tensions between health care professionals and patients.
Disclosure of Interest: None declared

DOI: 10.1136/annrheumdis-2017-eular.5072

\section{THU0763-HPR ADDRESSING THE ELEPHANT IN THE ROOM: A POSSIBLE NEW AND EFFECTIVE WAY TO INCREASE PATIENT ADHERENCE TO MEDICAL ADVICE}

G. Grønhaug ${ }^{1}$, S. Arnesen ${ }^{2} .{ }^{1}$ Department of Public Health and General Practice, Norwegian University of Science and Technology, Trondheim; ${ }^{2}$ Department of Comparative Politics, University of Bergen, Bergen, Norway

Background: Lack of Patient adherence to medical advice (PAMA) are recognized as an era of interest for the last decades ${ }^{1}$. There have been several initiatives to improve PAMA such as patient centred care, shared decision-making, introduction of e-health and m-health. Although they are proven better than usual care, neither of these initiatives is proven successful. Outcome of medical interventions depends on complex psychological and sociocultural factors of which many are uncontrolled by health professionals.

Objectives: In the present study we assess beliefs about priorities in public health care, and adherence to medical advice to establish a novel approach to increase PAMA.

Methods: The Norwegian Citizen Panel (NCP) ${ }^{2}$ is an experimental survey. Respondents are randomized to answer similar questions with slightly different wording. NCP is currently about 5000 respondents based on random selection performed by the Norwegian people register. The present study is based on responses to two question experiments from NCP adressing beliefs about priorities in public health care, and adherence to medical advice. The question on priorities in health care is divided in six groups (two control group, four experimental). The question on adherence is divided in three groups (one control group, two experimental). All questions are answered with a seven point Likert scale.

\begin{tabular}{|c|c|c|c|c|c|}
\hline \multirow[t]{2}{*}{$\begin{array}{l}\text { Question } \\
\mathrm{nr}\end{array}$} & \multirow[t]{2}{*}{ Question phrases } & \multirow[t]{2}{*}{ Result } & \multicolumn{2}{|c|}{$\begin{array}{l}\text { Confidence } \\
\text { Interyall } 95 \%\end{array}$} & \multirow[t]{2}{*}{$\mathrm{n}=$} \\
\hline & & & $\begin{array}{l}\text { Lower } \\
\text { bound }\end{array}$ & $\begin{array}{l}\text { Upper } \\
\text { bound }\end{array}$ & \\
\hline 1 & $\begin{array}{l}\text { Prioritising waiting lists for } \\
\text { surgery }\end{array}$ & & & & \\
\hline 1a & $\begin{array}{l}\text { Patients with severe illness are } \\
\text { treated first }\end{array}$ & 0,7442 & 0,7169 & 0,7714 & 271 \\
\hline $1 \mathrm{~b}$ & $\begin{array}{l}\text { Patients with severe illness are } \\
\text { treated first resulting in longer } \\
\text { waiting for one in your family }\end{array}$ & 0,7596 & 0,7329 & 0,7864 & 285 \\
\hline $1 \mathrm{c}$ & $\begin{array}{l}\text { Patients with severe illness are } \\
\text { treated first, resulting in longer } \\
\text { waiting for yourself } \\
\end{array}$ & 0,7600 & 0,7341 & 0,7860 & 266 \\
\hline $1 \mathrm{~d}$ & $\begin{array}{l}\text { Those who benefit most from } \\
\text { treatment are prioritised }\end{array}$ & 0,5226 & 0,4877 & 0,5576 & 265 \\
\hline $1 \mathrm{e}$ & $\begin{array}{l}\text { Those who benefit most from } \\
\text { treatment are prioritised, } \\
\text { resulting in longer waiting for } \\
\text { one in your family }\end{array}$ & 0,5560 & 0,5208 & 0,5912 & 277 \\
\hline $1 \mathrm{f}$ & $\begin{array}{l}\text { Those who benefit most from } \\
\text { treatment are prioritised, } \\
\text { resulting in longer waiting for } \\
\text { yourself }\end{array}$ & 0,5818 & 0,5465 & 0,6171 & 273 \\
\hline 2 & Treatment rejection & & & & \\
\hline $2 \mathrm{a}$ & Medical doctor denies treatment & 0,5009 & 0,4774 & 0,5245 & 539 \\
\hline $2 \mathrm{~b}$ & $\begin{array}{l}\text { Medical expertise does not } \\
\text { approve the treatment.* }\end{array}$ & 0,5361 & 0,5117 & 0,5604 & 564 \\
\hline $2 \mathrm{c}$ & $\begin{array}{l}\text { Medical expertise and patient } \\
\text { organisation agree on not } \\
\text { approving the treatment.* }\end{array}$ & 0,5730 & 0,5478 & 0,5982 & 523 \\
\hline
\end{tabular}

Question $1 \mathrm{a}$-f is used to assess beliefs on health care systems priorities. Question 2 assesses aspects of potential new ways to increase patient adherence. All questions are answered using a 7 point likert scale. Result is based on positive attitude regarding wording in the question

* Question phrases refer to how the physician explains to the patient why the treatment is rejected. 
Conclusions: This study is the first to use experimental survey to assess PAMA. The result indicates that healthcare priorities form a base of trust between health care providers and patients. It further indicates that PAMA might increase if the healthcare provider refers to national expertise and patient organisations beliefs of a given treatment. This finding is supported by psychological theories of meaning-making ${ }^{3}$.

Informing the patient about the views of the patient organisations and national expertise in the reasoning for a given treatment, may improve patient adherence to medical advices.

\section{References:}

[1] Costa E, Giardini A, Savin M, et al. Interventional tools to improve medication adherence: review of literature. Patient preference and adherence 2015;9:1303-14. doi: http://dx.doi.org/10.2147/PPA.S87551 [published Online First: 14.9 .2015$]$.

[2] Ivarsflaten E. Norwegian citizen panel Wave 2, 2014. First NSD edition, Bergen 2014 ed. University of bergen, 2014.

[3] Lewis J. From culturalism to transculturalism. lowa journal of cultural studies 2002;1:14-32.

Acknowledgements: Siv Mørkved for the suport and encouragement to do the study.

Disclosure of Interest: None declared

DOI: 10.1136/annrheumdis-2017-eular.1914

\section{THU0764-HPR WHAT MOVES THE RHEUMATOLOGIST? UNRAVELLING DECISION MAKING IN SSC REFERRAL - A QUALITATIVE STUDY}

J.K. Stöcker ${ }^{1,2}$, E. Cup ${ }^{3}$, R. Nijhuis-van der Sanden ${ }^{3}$, B. Staal ${ }^{2,3}$, M. Vonk ${ }^{3}$, F. van den Hoogen ${ }^{1,3}$, E. van den Ende ${ }^{1}$. ${ }^{1}$ Sint Maartenskliniek; ${ }^{2}$ Research group Musculoskeletal Rehabilitation, HAN University of Applied Sciences;

${ }^{3}$ Radboud university medical center, Nijmegen, Netherlands

Background: Well-coordinated multidisciplinary non-pharmacological care is considered to be a cornerstone in the management of patients with systemic sclerosis (SSc). However, unmet information and healthcare needs are found to be common in patients with SSc [1]. In addition, referrals by rheumatologists' do not always correspond with potential treatment goals as identified by health professionals (HP)[2].

Objectives: The aim of this study was to gain insight in the perspective of rheumatologists about the referral process of SSc patients to non-pharmacological care and to identify starting points for its optimisation.

Methods: Semi structured in-depth interviews were held with 13 out of 24 rheumatologists, specialised in SSc management, from different Dutch university and regional medical centres. The qualitative data analysis used an inductive thematic analysis by moving through a process of coding in layers of abstraction and interpretation: familiarization with data, generating initial codes, grouping similar codes in categories, discussing categories, searching for themes among categories, reviewing themes, defining and naming themes, and producing the final report.

Results: One major theme was identified as influencing decision making: "beliefs" and its three sub themes: a) beliefs about one's own professional role; b) beliefs about the patients' ability to take an active role in managing the disease and c) beliefs about the added value of non-pharmacological care. We also found an additional theme reflecting the "needs" of the rheumatologists regarding professional multidisciplinary collaboration (Figure 1). Another remarkable finding to be further explored was the discrepancy we found between the reliance of rheumatologists on established routines with regard to when and to whom to refer and the low confidence in HPs competencies on the other hand.

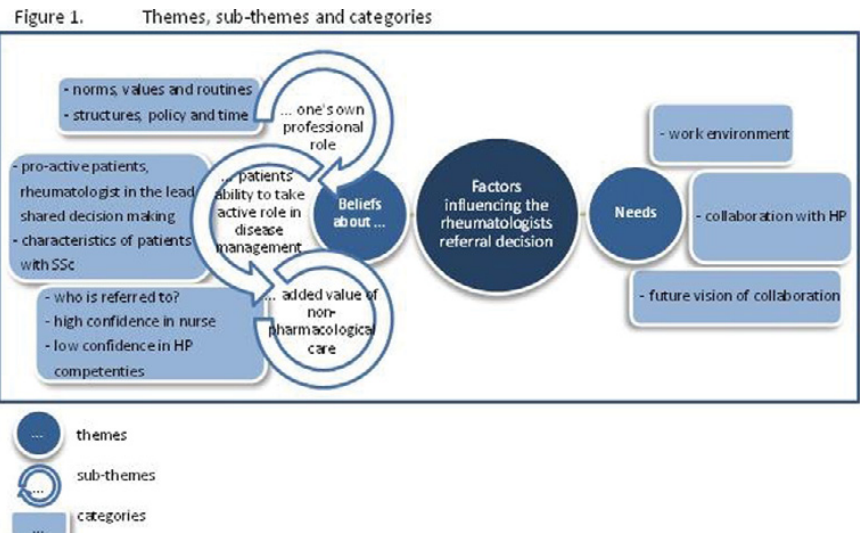

Conclusions: The results of our study give insight that rheumatologists base their referral decisions on complex reasoning mindlines and beliefs about their own professional role, the patient's role and HP competencies.

References:

[1] Willems, L. M., Kwakkenbos, L., Leite, C. C., Thombs, B. D., van den Hoogen,
F. J., Maia, A. C., \& van den Ende, C. M. (2014). Frequency and impact of disease symptoms experienced by patients with systemic sclerosis from five European countries. Clinical And Experimental Rheumatology, 32(6 Suppl 86), S-88-93.

[2] Schouffoer, A., Zirkzee, E., Henquet, S., Caljouw, M., Steup-Beekman, G., Laar, J., \& Vlieland, T. (2011). Needs and preferences regarding health care delivery as perceived by patients with systemic sclerosis. Clinical Rheumatology, 30(6), 815-824. doi:10.1007/s10067-010-1645-6.

Disclosure of Interest: None declared

DOI: 10.1136/annrheumdis-2017-eular.5886

\section{THU0765-HPR PATIENT SATISFACTION AND SELF-MONITORING OF CHRONIC INFLAMMATORY ARTHRITIS}

K. Grønning ${ }^{1,2}$, E.K. Lyngvær ${ }^{2}$, A.S. Magnussen ${ }^{2}$, E. Rødevand ${ }^{2}$. ${ }^{1}$ Department of Public Health and Nursing, Norwegian University of Science and Technology; ${ }^{2}$ Rheumatology, University Hospital in Trondheim, Trondheim, Norway

Background: Effective drug treatment for patients with inflammatory arthritis have brought a major proportion of patients in clinical remission. The need for regular follow-up intervals in specialized care is less; patients take greater responsibility for their own care, and patients request access to more flexible health care services. As a result of this development, the University Hospital, St.Olavs Hospital, Department of Rheumatology, has developed a on-demand pathway (PORS) for patients with inflammatory arthritis (RA, PsA and AS) in clinical remission or low disease-activity aiming for increased patient responsibility and flexibility.

Objectives: The aim of this study was to investigate patients' satisfaction with PORS regarding disease status, treatment, knowledge, responsibility, and cooperation with health care professionals.

Methods: We conducted a quest-back survey for patients included in PORS for $\geq 1$ year in the period from June 2016 to October 2016. The survey contained 10 questions about the pathway. The response alternatives and scoring were: not at all $=1$, to a small extent $=2$, to some extent $=3$, to a large extent $=4$, to a very large extent $=5$, and not relevant $=0$.

Results: We identified 1048 eligible patients, 10 invitations were returned (unknown address), and 312 responded (30\%). The descriptive analyses (see table) showed that the patients in general considered their disease activity to be in a stable phase. The cooperation with their general practitioner was good, they had to some or large extent sufficient knowledge to take responsibility for the blood test controls and adhere to prescribed medication. The patients were to some extent satisfied with the renewals of prescriptions and access to health professionals. The patients were less satisfied with the "promise" of getting outpatient appointments within 14 days if needed. Finally, the patients would largely recommend PORS to other patients.

\begin{tabular}{|c|c|c|c|}
\hline PORS Questions & Mean (SD) & Median & Not relevant \\
\hline Is the disease activity in a stable phase now? & $3.70(0.95)$ & 4 & - \\
\hline $\begin{array}{l}\text { Has the disease activity been in a stable phase since you } \\
\text { became included in PORS? }\end{array}$ & p) & 4 & $1 \%$ \\
\hline $\begin{array}{l}\text { Do you have sufficient knowledge to take responsibility and } \\
\text { carry out the routine blood test controls? }\end{array}$ & $4.21(0.94)$ & 4 & $1 \%$ \\
\hline $\begin{array}{l}\text { Do you have sufficient knowledge and confidence to take } \\
\text { your medications as prescribed? }\end{array}$ & $4.26(0.91)$ & 4 & $1 \%$ \\
\hline $\begin{array}{l}\text { Do the renewals of medications prescriptions work okay? } \\
\text { Do you get in touch with the Health Professionals at the }\end{array}$ & $3.16(2.1)$ & 4 & $26,6 \%$ \\
\hline $\begin{array}{l}\text { Do you get in touch with the Health Professionals at the } \\
\text { Rheumatology Department by phone when you need to? }\end{array}$ & $3.61(1.6)$ & 4 & $11,5 \%$ \\
\hline $\begin{array}{l}\text { Was the waiting time for an appointment at the department } \\
\text { too long before you became included in PORS? }\end{array}$ & $2.50(1.33)$ & 2 & $6,7 \%$ \\
\hline $\begin{array}{l}\text { Do you get the outpatient appointment within } 14 \text { days } \\
\text { if you need one? }\end{array}$ & $2.28(2.06)$ & 2 & $40,7 \%$ \\
\hline $\begin{array}{l}\text { Do you have a good cooperation with your general } \\
\text { practitioner? }\end{array}$ & $4.05(1.07)$ & 4 & $1,3 \%$ \\
\hline Would you recommend PORS to other patients? & $3.91(1.33)$ & 4 & $0,3 \%$ \\
\hline
\end{tabular}

Conclusions: We found that patients with inflammatory arthritis in general were satisfied with a management pathway encouraging greater responsibility for managing their own care and the possibility for more flexible contacts with the health care services. However, fullfilling the promise of outpatient appointments within 14 days were not always possible to achieve.

Acknowledgements: We would like to thank the local Rheumatology fund for financing the project.

Disclosure of Interest: None declared

DOI: 10.1136/annrheumdis-2017-eular.3223

\section{THU0766-HPR REFERRAL TO TELECARE. A NEW MODEL OF RHEUMATIC PATIENT FOLLOW-UP}

L. Cano Garcia, N. Mena-Vazquez, S. Manrique-Arija, F.G. Jiménez-Núñez, I. Ureña-Garnica, C. Domic-Bueno, M. Rojas-Gimenez, C. Fuegos-Varela, M.V. Irigoyen-Oyarzabal, E. Vilchez-Ocaña, A. Fernández-Nebro. Rheumatology, Hospital Regional Universitario de Málaga, Málaga, Spain

Objectives: To analyze the medical ramifications that are made to the consultation 